\section{SAT0271 RELATIONSHIP BETWEEN ANTI-MDA5 ANTIBODIES AND CANCER: RETROSPECTIVE ANALYSIS OF AN INTERNATIONAL AND MULTIDISCIPLINARY COHORT}

Ludovico De Stefano ${ }^{1}$, Santos Castañeda ${ }^{2}$, Ellen De Langhe ${ }^{3}$, Jörg Distler ${ }^{4}$, Johannes Knitza $^{4}$, Ilaria Cavazzana ${ }^{5,6}$, Alain Meyer ${ }^{5,7}$, Jorge Rojas-Serrano ${ }^{8}$, Eugenio Arrigoni ${ }^{9}$, Federica Furini ${ }^{10}$, Marcello Govoni ${ }^{10}$, Paola Parrocchini ${ }^{11}$, Giovanni Zanframundo ${ }^{1}$, José Antonio P. Da Silva ${ }^{12}$, Elisa Pedrollo ${ }^{13}$, Florenzo lannone ${ }^{14}$, Carlomaurizio Montecucco ${ }^{1}$, Lorenzo Cavagna ${ }^{1}$, The AENEAS collaborative group. ${ }^{1}$ Rheumatology, Policlinico S. Matteo Foundation, European Reference Network ReCONNET, pavia, Italy, ${ }^{2}$ Rheumatology, Hospital Universitario de la Princesa, madrid, Spain; ${ }^{3}$ Rheumatology, University Hospital, leuven, Belgium; ${ }^{4}$ Internal Medicine, University Hospital, erlangen, Germany; ${ }^{5}$ European Reference Network ReCONNET, pavia, Italy; ${ }^{6}$ Rheumatology, AOU Spedali Civili, brescia, Italy, ${ }^{7}$ Hopitaux Universitaries de Strasbourg, strasbourg, France; ${ }^{8} I L D$ and Rheumatology Unit, Instituto National de Enfermedades Respiratorias, mexico city, Mexico; ${ }^{9}$ Rheumatology Unit, Ospedale Guglielmo da Saliceto, piacenza, Italy; ${ }^{10}$ Rheumatology, AOU S. Anna, ferrara, Italy, ${ }^{11}$ ISOD Immunologia e Ter. Cell., AOU Careggi, firenze, Italy, ${ }^{12}$ 12. Rheumatology, Centro Hospitalar e Universitatio de Coimbra, coimbra, Portugal; ${ }^{13}$ Rheumatology,

Policlinico S. Matteo Foundation, pavia, Italy; ${ }^{14}$ Rheumatology Unit, Department of Emergency and Organ Transplantations, Policlinico, bari, Italy

Background: Myositis specific antibodies play a central role in the assessment of idiopathic inflammatory myopathies (IIMs) as their presence may indicate specific disease subsets/manifestations or cancer risk. At present, anti-MDA5 antibodies have been associated with the occurrence of rapidly progressive interstitial lung disease (RP-ILD), a life-threatening condition, generally refractory to treatment.

Objectives: To describe the relationship between malignancy and antiMDA5 antibodies in IIMs.

Methods: Patients with anti-MDA5+ IIMs and a history of cancer were included in this study. Data were retrospectively collected. Because of the lack of RP-ILD shared definitions, we defined RP-ILD as an admission to the Intensive Care Unit (ICU) for IIMs related respiratory insufficiency.

Results: In our cohort ( $\mathrm{n}=133,67 \%$ females) we identified 17 patients (13\%) with a history of cancer (8 males [47\%], 9 females [53\%]; median age at IIMs onset 62 years [IQR 53-67], at cancer diagnosis 56 years [IQR 51-66]). All but 1 patient had solid tumours, $5(29 \%)$ had breast cancer. In 9 patients $(53 \%)$ cancer diagnosis ranged \pm 3 years from IIMs onset; in 3 patients the delay exceeded 120 months. Three patients (18\%) developed RP-ILD respectively 82, 66 and 0 months after the diagnosis of cancer. Four (24\%) patients died respectively 0 (neoplasia), 0 (RP-ILD in ICU, diagnosis of cancer after an autopsy), 7 (neoplasia) and 66 (infection after RP-ILD in ICU) months after cancer diagnosis. The 13 surviving patients had a median rheumatological follow-up of 47 months (IQR 19-84) and an oncological follow-up of 57 months (IQR 10130). Interestingly, in the overall cohort $66 \%$ of patients without cancer (76 out of 116) had less than 3 years of follow-up. Of the 22 RP-ILD patients without neoplasia 14 died, 11 during ICU admission. In the latter patients, we could not rule out an occult neoplasia due to the emergency of the situation. Only one patient, with a 18 month history of IIMs before ICU admission, underwent autopsy and was reported negative for cancer.

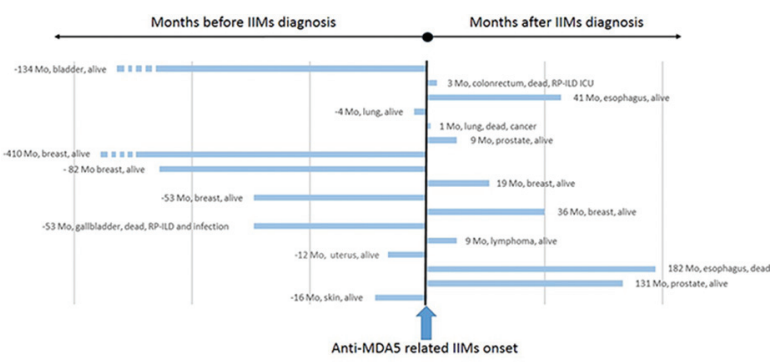

Figure 1: temporal relationship between anti-MDAS related IIMs and cancer diagnosis, compre
neoplasia site and outcome; legend: IIMs, Idiopathic Inflammatory Myopathies; Mo= months

Conclusion: This is the first study addressed to tackle the relationship between cancer and anti-MDA5+ IIMs. Although in some cases no clear relationship between IIMs and cancer can be proved because of the time gap, in others the timing of occurrence of cancer and IIMs was very close, suggesting a link between these manifestations. Finally, we emphasize the importance of an accurate neoplasm screening in anti-MDA5+ RP-ILD, because treatment refractoriness could suggest the paraneoplastic nature of the manifestation.

\section{REFERENCES}

[1] Barsotti S, et al. Rheumatol Int 2014

[2] Lu X, et al. PLoS One 2014

Disclosure of Interests: Ludovico De Stefano: None declared, Santos Castañeda Consultant for: Amgen, BMS, Pfizer, Lilly, MSD, Roche, Sanofi, UCB, Ellen De Langhe: None declared, Jörg Distler: None declared, Johannes Knitza: None declared, Ilaria Cavazzana: None declared, alain meyer: None declared, Jorge Rojas-Serrano: None declared, eugenio arrigoni: None declared, Federica Furini: None declared, Marcello Govoni Paid instructor for: Pfizer, Roche, Speakers bureau: Pfizer, Abbvie, MSD, Roche, Eli-Lilly, Celgene, Sanofi, Janssen, paola parrocchini: None declared, Giovanni Zanframundo: None declared, José Antonio P. da Silva: None declared, elisa pedrollo: None declared, Florenzo lannone Consultant for: $\mathrm{F}$ lannone has received consultancy fees and/or speaker honoraria from Pfizer, AbbVie, MSD, BMS, Novartis, Lilly, UCB outside this work, Speakers bureau: $F$ lannone has received consultancy fees and/or speaker honoraria from Pfizer, AbbVie, MSD, BMS Novartis, Lilly, UCB outside this work, Carlomaurizio Montecucco Speakers bureau: AbbVie, Bristol-Myers Squibb, Celgene, Sanofi, Genzyme, Lilly, MSD, Pfizer, UCB, Lorenzo Cavagna: None declared DOI: 10.1136/annrheumdis-2019-eular.4565

\section{SAT0272 RITUXIMAB SIGNIFICANTLY DIMINISHES CD86+ B CELLS IN SYSTEMIC SCLEROSIS}

Barbara Dreo ${ }^{1}$, Barbara Priett ${ }^{2,3}$, Selina Kofler ${ }^{2,3}$, Harald Sourij ${ }^{2,3}$, Angelika Lackner ${ }^{1}$, Florentine Fürst-Moazedi ${ }^{1}$, Monica D'orazio ${ }^{1}$, Martin Stradner ${ }^{1}$, Winfried Graninger ${ }^{1}$, Hans-Peter Brezinsek'. ${ }^{1}$ Medical University of Graz, Division of Rheumatology and Immunology, Graz, Austria; ${ }^{2} \mathrm{CBmed} \mathrm{GmbH}-$ Center for Biomarker Research in Medicine, Graz, Austria; ${ }^{3}$ Medical University of Graz, Division of Endocrinology and Diabetology, Graz, Austria

Background: Rituximab (RTX) is a monoclonal antibody that targets the CD20 surface marker. This results in a reduction of $\mathrm{CD}^{2} 0^{+}$immune cell populations, foremost B cells. B cell depletion via RTX was found to be beneficial for patients suffering from systemic sclerosis (SSc), leading to an improvement of skin fibrosis and autoimmunity $(1,2)$. However, little is known about the influence of RTX on specific B subsets in SSc.

Objectives: The purpose of this study was to further characterize the effect of RTX on B cell populations in patients with SSc.

Methods: Peripheral blood samples from 37 patients suffering from SSc (mean age: 54 years \pm 1.64 SEM, female ratio: 0.78 ) and 10 age-matched healthy participants were drawn over a sampling period of 2 years. $20 \mathrm{SSc}$ patients in this study group were at the time under RTX treatment and the modified Rodnan Skin score (mRSS) was measured before and after treatment start. The percentage of $\mathrm{CD} 19^{+/-}, \mathrm{CD} 20^{+/-}$lymphatic cells and $\mathrm{CD} 19^{+} \mathrm{CD} 20^{+} \mathrm{B}$ cells co-expressing either CD5, CD24, CD27 or CD86 on their surface was done by staining freshly isolated PBMCs. A quantitative flow cytometric beadbased assay (QuantiBRITE PE kit from Becton Dickinson) was used for the estimation of CD19 antibodies bound per cell. All cytometric measurements were performed using a standardized BD LSRFortessa platform.

Results: RTX induced a significant decrease in mRSS from $19.7 \pm 2.8$ to $8.1 \pm 1.7$ (mean \pm SEM; $\mathrm{p}<0.000$ ). In addition, $\mathrm{CD} 19^{-} \mathrm{CD} 20^{+}$cells were significantly diminished as a result of the treatment. Thus, the frequency of $\mathrm{CD}_{1}{ }^{-} \mathrm{CD} 2 \mathrm{O}^{+}$cells in the non-treatment group was $1.3 \% \pm$ $0.3 \%$ compared to $0.7 \% \pm 0.2 \%(p=0.048)$. Within the B cell population $33.3 \% \pm 3.8 \%$ were positive for CD86, a checkpoint molecule for the activation of $\mathrm{T}$ cells during an immune response. RTX treatment significantly decreased this B cell population to $11.2 \% \pm 4.7 \%$ ( $p=$ 0.039). Quantification of the number of CD19 molecules on the surface of $\mathrm{CD}_{1} 9^{+} \mathrm{CD} 20^{+} \mathrm{B}$ cells revealed a significantly lower number in SSc patients compared to healthy participants. The mean \pm SE of molecules per cell was $6862 \pm 625$ and $7449 \pm 569$, respectively ( $\leq$ 0.001 ).

Conclusion: RTX treatment in SSc might not only be effective by reducing $B$ cells but also by down regulation of the CD86 B cell surface marker on B cells. This would indicate that B cells under RTX treatment are less capable of activating $T$ cells.

\section{REFERENCES}

[1] Lafyatis R, Kissin E, York M, Farina G, Viger K, Fritzler MJ, et al. B Cell Depletion With Rituximab in Patients With Diffuse Cutaneous Systemic Sclerosis. 2009;60(2):578-83. 